\title{
Foam mat drying of mango: Effect of processing parameters on the drying kinetic and product quality
}

\section{Ana María Chaux-Gutiérrez, Adriana Barbosa Santos, Diana Maria Granda- Restrepo \& Maria Aparecida Mauro}

To cite this article: Ana María Chaux-Gutiérrez, Adriana Barbosa Santos, Diana Maria GrandaRestrepo \& Maria Aparecida Mauro (2017) Foam mat drying of mango: Effect of processing parameters on the drying kinetic and product quality, Drying Technology, 35:5, 631-641, DOI: 10.1080/07373937.2016.1201486

To link to this article: https://doi.org/10.1080/07373937.2016.1201486

Jul 2016.

Published online: 27 Feb 2017.

Submit your article to this journal $\pi$

Џ Article views: 228

View Crossmark data ¿

Citing articles: 4 View citing articles 


\title{
Foam mat drying of mango: Effect of processing parameters on the drying kinetic and product quality
}

\author{
Ana María Chaux-Gutiérreza, Adriana Barbosa Santos ${ }^{b}$, Diana Maria Granda-Restrepoc, \\ and Maria Aparecida Mauro ${ }^{\mathrm{a}}$ \\ aDepartment of Food Engineering and Technology, Institute of Bioscience, Language and Physical Sciences (IBILCE), UNESP-São Paulo State \\ University, São José do Rio Preto, SP, Brazil; 'bepartment of Computer Science and Statistic, Institute of Bioscience, Language and Physical \\ Sciences (IBILCE), UNESP-São Paulo State University, São José do Rio Preto, SP, Brazil; 'Department of Food, Pharmaceutical and Food Science \\ Faculty, Universidad de Antioquia, Medellin, Antioquia, Colombia
}

\section{ABSTRACT}

This study investigated the foam mat drying process parameters (temperature and concentration of foaming agents, albumin, and an emulsifier blend) and evaluated their effects on drying kinetics, color, carotenoid retention, and solubility of the mango pulp powder. Fick's model was able to represent the foam mat drying kinetics. The foaming agents and high temperatures enhanced the carotenoid retention. This was explained by the greater effective water diffusion coefficients that allowed obtaining products with low moisture contents and water activities in short processing times of up to $3 \mathrm{~h}$, with high carotenoid retention and color maintenance.

\section{KEYWORDS}

Albumin; carotenoid; color parameters; diffusion coefficients; emulsifier blend; experimental design

\section{Introduction}

The mango (Mangifera indica L) stands out among the exotic fruits produced and exported by Brazil, and is considered to be an agricultural product of great economic importance with a production of $1,163,000$ thousand tons in 2013. ${ }^{[1]}$ The mango is also nutritionally attractive due to its $\beta$-carotene content, which contributes to the nutritional value since it is an antioxidant and vitamin A precursor. The mango is also a source of vitamin $\mathrm{C}$ and phenolic compounds. ${ }^{[2]}$ However, it is highly perishable and can deteriorate in short periods of time and hence its postharvest handling is an important factor in the production chain. Thus drying appears as an alternative to prolong the useful life of this product, ${ }^{[3]}$ drying being one of the oldest and most widely used methods to conserve fruits. ${ }^{[4]}$ However, conventional hot-air drying presents various disadvantages such as the need for long processing times at elevated temperatures, making the process energetically expensive, causing degradation of vitamins, antioxidant substances and dietetic fibers, and affecting some of the sensory properties such as color, taste, and texture. Thus new drying methods, such as foam mat drying, have been proposed, aimed at maintaining the nutritional characteristics of the product and decreasing energy consumption. ${ }^{[5,6]}$ Foam mat drying involves converting a liquid or semiliquid material into a stable foam by beating it with the addition of foaming agents, which produce and stabilize the foam, followed by drying in thin layers with hot air at atmospheric pressure, ${ }^{[7-9]}$ microwave, ${ }^{[10]}$ or freeze drying ${ }^{[1]}$ and finally grinding the dried material to obtain a powder. This technique has been investigated for the production of fruit juice and/or pulp powders, such as mango, ${ }^{[9,12,13]}$ apple, ${ }^{[14]}$ Gac fruit (Momordica cochinchinensis) aril, ${ }^{[15]}$ muskmelon (Cucumis melo), ${ }^{[16]}$ sour cherry, ${ }^{[17]}$ papaya, ${ }^{[8]}$ pineapple ${ }^{[6]}$ purple-cherry, ${ }^{[18]}$ and blackcurrant. ${ }^{[19]}$ It has also been applied to obtain cowpea flour, ${ }^{[20]}$ albumin poder, ${ }^{[11]}$ shrimp powder, ${ }^{[21]}$ and yacon juice powder. ${ }^{[22]}$ Various foaming agents have been tested, and in all cases the authors managed to obtain formulations and procedures resulting in products with good sensory quality and fast drying rates. For instance, Kadam et al. ${ }^{[12]}$ used milk as the foaming agent to optimize the production of mango pulp. Rajkumar et al. ${ }^{[13]}$ also investigating the production of mango pulp, performed a large-scale study concerning the expansion capacity and stability of different foaming agents, and the influence of the thickness of the layers and drying temperature on the mango powder characteristics. Rajkumar et al. ${ }^{[9]}$ also developed a continuous foam dryer, where they tested the most effective conditions selected in an earlier study, which were $10 \%$ albumin with $0.5 \%$ methyl cellulose to stabilize the foam,

CONTACT Ana María Chaux-Gutiérrez anachauxg@gmail.com Department of Food Engineering and Technology, Institute of Bioscience, Language and Physical Sciences (IBILCE), UNESP-São Paulo State University, Rua Cristovão Colombo 2265, 15054-000 São José do Rio Preto, SP, Brazil. 
1-mm-thick layers and a temperature of $60^{\circ} \mathrm{C}$. Nevertheless, there is still much to be learnt concerning this technology, especially with respect to the modeling of the process, which would provide subsidies for the design and control of foam mat drying. Thus, with the objective of evaluating the influence of the foam mat drying process parameters on drying kinetics and the physical and nutritional properties of the mango pulp powder, this work investigated the effects of temperature, the EMB concentration, ALB concentration, and the EMB-ALB mixture on diffusion coefficients, color maintenance, carotenoid content, and retention, and the solubility of the mango pulp powder.

\section{Materials and methods}

\section{Raw materials}

Mangoes (M. indica L. cv. "Tommy Atkins"), cultivated in Petrolina, Pernambuco State (Brazil), were purchased in December 2013 at the São José do Rio Preto Supply Center (CEAGESP; São José do Rio Preto, São Paulo, Brazil), and maintained at room temperature until mature. Maturity was determined visually by observing a red-yellow color of the fruit skin and a firm consistency on touching. Once mature, the pulp was obtained and stored in a freezer at $-18^{\circ} \mathrm{C}$ in high-density polyethylene bags. Commercial albumin powder (ALB) of the brand Naturovos (Salvador do Sul, RS, Brazil) was used and a commercial grade mixture of distilled fatty acid monoglycerides, sorbitan monostearate, and sorbitan monostearate polyoxyethylene (EMB) (Duas Rodas Industrial, Jaraguá do Sul, SC, Brazil).

\section{Methods}

\section{Foam preparation}

Before foam preparation, the frozen pulp was thawed at refrigeration temperature $\left(5^{\circ} \mathrm{C}\right)$ for $24 \mathrm{~h}$. For foam preparation, approximately $300 \mathrm{~g}$ of thawed pulp was added to the mixer bowl and quantities of ALB and EMB or their combinations added according to the experimental design shown in Table 1. The mixture was then beaten in a 3-speed RI 7110 domestic beater (Philips Walita, Brazil) for $5 \mathrm{~min}$. The first minute was at medium speed, aimed at dissolving the foaming agents, and the remaining $4 \mathrm{~min}$ at high speed for better incorporation of the air in the emulsion.

\section{Drying}

The mango foams produced with the different emulsifiers were dried with air heated at two temperatures, 60 and $80^{\circ} \mathrm{C}$, with an air speed of $1.0 \mathrm{~m} \cdot \mathrm{s}^{-1}$ and layer thickness of $3 \mathrm{~mm}$. The dryer used had a fixed bed with
Table 1. $2^{3}$ Factorial experimental design with coded and noncoded factors applied to the foam mat drying of mango.

\begin{tabular}{cccc}
\hline & \multicolumn{3}{c}{ Factors } \\
\cline { 2 - 4 } Trial & $\begin{array}{c}\text { Temperature } \\
\left({ }^{\circ} \mathrm{C}\right), x_{1}\end{array}$ & $\begin{array}{c}\text { EMB concentration } \\
\left(\mathrm{kg} \mathrm{EMB} \cdot 100 \mathrm{~kg}^{-1}\right. \\
\mathrm{pulp}), x_{2}\end{array}$ & $\begin{array}{c}\text { ALB concentration } \\
\left(\mathrm{kg} \mathrm{ALB} \cdot 100 \mathrm{~kg}^{-1}\right. \\
\text { pulp), } x_{3}\end{array}$ \\
\hline 1 & $60(-1)$ & $2(1)$ & $10(1)$ \\
2 & $80(1)$ & $0(-1)$ & $0(-1)$ \\
3 & $60(-1)$ & $2(1)$ & $0(-1)$ \\
4 & $60(-1)$ & $2(1)$ & $0(-1)$ \\
5 & $80(1)$ & $2(1)$ & $10(1)$ \\
6 & $80(1)$ & $2(1)$ & $10(1)$ \\
7 & $60(-1)$ & $0(-1)$ & $0(-1)$ \\
8 & $80(1)$ & $0(-1)$ & $0(-1)$ \\
9 & $60(-1)$ & $0(-1)$ & $10(1)$ \\
10 & $60(-1)$ & $0(-1)$ & $0(-1)$ \\
11 & $80(1)$ & $0(-1)$ & $10(1)$ \\
12 & $80(1)$ & $2(1)$ & $0(-1)$ \\
13 & $60(-1)$ & $0(-1)$ & $10(1)$ \\
14 & $60(-1)$ & $2(1)$ & $10(1)$ \\
15 & $80(1)$ & $0(-1)$ & $10(1)$ \\
16 & $80(1)$ & $2(1)$ & $0(-1)$ \\
\hline ALB & 0 & & $(1)$
\end{tabular}

$A L B$, mango powder with albumin (10 kg ALB $\cdot 100 \mathrm{~kg}^{-1}$ pulp); EMB, mango powder with emulsifier blend (2 $\mathrm{kg} \mathrm{EMB} \cdot 100 \mathrm{~kg}^{-1}$ pulp).

forced convection of the heated air using a centrifugal fan controlled by a frequency inverter (CWF10, WEG, Jaraguá do Sul, Brazil), which allows one to change the air speed. The air was heated by electric resistances and the temperature controlled using a microprocessor digital controller (N440, Novus, Porto Alegre, Brazil) with a J-type thermocouple. The relative humidity and air velocity were measured by a humidity sensor (DO9861T-R1m Delta Ohm, Caselle di Selvazzano, Itália) and the hot wire anemometer (HD403TS 1, Delta $\mathrm{Ohm})$, respectively.

For each trial, the foams were filled into specially made $30 \times 30 \mathrm{~cm}^{2}$ aluminum trays with 3 -mm-high borders. The trays were previously weighed and identified, the maximum foam weight being $100 \mathrm{~g}$. The trays containing the samples were weighed every 10 min during the first hour of drying and then every $15 \mathrm{~min}$ to constant weight. After each weighing, the tray was turned through $180^{\circ}$ and placed in a new vertical position in the drying chamber. After reaching equilibrium, the dried foam block was removed with the help of a spatula for subsequent grinding. Curves were drawn using the data for water content on a dry basis as a function of drying time. The water content, color, and carotenoid contents were determined on the samples before and after the drying steps.

\section{Drying kinetics}

The drying mechanisms involved with foam drying could be compared with those attributed to porous material drying, which has been very well described in the literature. ${ }^{[23]}$ The solids that form the bubbles would be considered a skeleton with water saturating the wallsurfaces and occupying narrow spaces and capillaries. In 
the initial stages of drying, water should migrate mainly by capillarity but shortly after by creeping along the walls. Also, as drying proceeds, liquid water bridges are formed in narrow spaces and water should migrate by successive evaporation-condensation between the water bridges. ${ }^{\text {[23] }}$ The vapor flow will predominate only at the last stage, when the drying takes place in all material, and an equilibrium state will be reached if the amount of water that vaporizes equals the amount that condenses. ${ }^{[23]}$

For foam mat drying, it was considered that the drying process can be described by the falling-rate period, where the liquid diffusion is the principal flow mechanism. Thus, the drying kinetics was evaluated based on Fick's second law, ${ }^{[24]}$ presented below in its modified form in terms of the mass fractions on a dry weight basis, considering the concentration of the solids to be constant:

$$
\frac{\partial X}{\partial t}=D_{\text {eff }} \nabla^{2} X
$$

where $X$ is the mass fraction of water on a dry weight basis $\left(\mathrm{kg} \cdot \mathrm{kg}^{-1}, \mathrm{db}\right), D_{\text {eff }}$ is the effective water diffusion coefficient $\left(\mathrm{m}^{2} \cdot \mathrm{s}^{-1}\right)$, and $t$ is the time $(\mathrm{s})$.

To determine the diffusivity coefficient, the infinite plate geometry was assumed in the diffusion model, with only one surface exposed to the drying air. Moisture migration occurred in the direction of the thickness of the material. Thus considering that water migration only occurred in the direction $z$, that the moisture was uniformly distributed in the foam at the initial moment, and that external resistance to moisture transference was insignificant, Eq. (1) would be subjected to the following conditions:

$$
\begin{gathered}
t=0, \text { for the whole of } z, X=X_{0} \\
t>0, z=0,\left.\frac{\partial X}{\partial z}\right|_{z=0}=0 \\
t>0, z=L, X=X_{\mathrm{eq}}
\end{gathered}
$$

where $X_{0}$ and $X_{\text {eq }}$ represent the water content on a dry weight basis $\left(\mathrm{kg} \cdot \mathrm{kg}^{-1}, \mathrm{db}\right)$ at the initial moment $(t=0)$ and at equilibrium (eq).

The effective diffusion coefficient was treated as constant. Effects of the temperature gradient which could affect the phenomenon of water transference in the product were assumed negligible. Hence, these were encompassed by the effective diffusion coefficient that also absorbs the effects of shrinkage, porosity, and tortuosity. The analytical solutions are applicable to solids with simple, constant geometry throughout the process, ${ }^{[2]}$ although widely used in drying studies, even with highly deformable solids.
In order to determine the effective water diffusion coefficients according to Fick's second law, applied to an infinite plate and subject to the initial condition and to the boundary conditions given by Eqs. (2)-(4), the analytical solution of Eq. (1) integrated throughout the distance $z$ was used ${ }^{[24]}$ :

$$
\begin{aligned}
M R= & \frac{\bar{X}-X_{\mathrm{eq}}}{X_{0}-X_{\mathrm{eq}}}=\frac{8}{\pi^{2}} \sum_{n=0}^{\infty} \frac{1}{(2 n+1)^{2}} \\
& \exp \left[-\frac{(2 n+1)^{2} \cdot \pi^{2} \cdot D_{\mathrm{eff}} \cdot t}{4 L^{2}}\right]
\end{aligned}
$$

where $D_{\text {eff }}$ is the effective water diffusivity $\left(\mathrm{m}^{2} \cdot \mathrm{s}^{-1}\right)$, moisture ratio (MR) is the nondimensional aspect of the water concentration, $\bar{X}$ represents the mean water content on a dry weight basis $\left(\mathrm{kg} \cdot \mathrm{kg}^{-1}\right.$ dry matter) in time $t(\mathrm{~s}), X_{\text {eq }}$, and $X_{0}$ represent the water contents on a dry weight basis $\left(\mathrm{kg} \cdot \mathrm{kg}^{-1}\right.$ dry matter) at equilibrium and at the initial moment, respectively, and $L$ is the thickness of the plate exposed to the drying air at just one of its faces. The analytical solutions of Fick's law are applicable to solids with simple, constant geometry throughout the process, ${ }^{[24]}$ although widely used in drying studies, even with highly deformable solids. However, in the present study a simplified procedure that uses shrinkage consideration was applied. In an approximate way, the thickness of the plate $L$ was considered as a linear function of the moisture content of the foam. The incorporation of thicknesses that vary as a function of moisture content in the integrated analytical solutions of the diffusion equation has proved to be a suitable method to decrease the influence of shrinkage on the effective diffusion coefficients determined by these equations. This diminished the discrepancies resulting from the consideration of the initial thickness as constant throughout the whole drying process, for highly deformable materials. ${ }^{[25]}$

\section{Color analyses}

The colors of the foams and mango powders were determined using a ColorFlex model $45 / 0$ spectrophotometer (Hunterlab, USA) with the D65 illuminant and observer at $10^{\circ}$. The 4.10 version universal software was used to determine the absolute values of $L^{*}, a^{*}$, and $b^{*}$. The chroma $\left(C^{*}\right)$, which expresses the degree of intensity or saturation of the color (Eq. 6), and also the hue angle $\left(h^{*}\right)$, which represents the tonality of the color (Eq. 7), ${ }^{[26]}$ were also calculated:

$$
\begin{gathered}
C^{*}=\sqrt{\left(a^{*}\right)^{2}+\left(b^{*}\right)^{2}} \\
h^{*}=\operatorname{arctg}\left(\frac{b^{*}}{a^{*}}\right)
\end{gathered}
$$




\section{Carotenoids and percent retention}

The total carotenoid content was determined according to the methodology described by Rodriguez-Amaya and Kimura. ${ }^{[27]}$ The carotenoids were extracted using acetone from approximately $2 \mathrm{~g}$ of raw sample and $1 \mathrm{~g}$ of dry sample using the Turratec model TE-102 equipment (Tecnal, Brazil). To facilitate the extraction, the raw samples remained in the acetone for $10 \mathrm{~min}$, and the dry samples were previously rehydrated in distilled water for $20 \mathrm{~min}$. The absorbance of the extracts was measured at the wavelength of maximum absorption $(450 \mathrm{~nm})$ using a model SP-220 UV-visible spectrophotometer (Biospectro, Brazil). All analyses were performed in duplicate. The retention of the carotenoids was calculated according to Murphy et al. ${ }^{[28]}$ (Eq. 8):

$$
\operatorname{Ret}(\%)=\frac{C_{f} \cdot M_{f}}{C_{i} \cdot M_{i}} \cdot 100
$$

where Ret is the percent total carotenoid retention, $C_{f}$ is the final total carotenoid content of the samples, $C_{i}$ is the initial total carotenoid content ( $\mu \mathrm{g} \beta$ carotene $\cdot \mathrm{g}^{-1}$ total), $M_{f}$ is the final sample mass, and $M_{i}$ is the initial sample mass ( $\mathrm{g}$ ).

\section{Solubility}

The solubility of the powders was determined according to Caparino et al. ${ }^{[29]}$ with some modifications. A quantity of $0.5 \mathrm{~g}$ of sample of powder was dispersed in $50 \mathrm{~mL}$ of distilled water and mixed at high speed $(\sim 13,000 \mathrm{rpm})$ for $5 \mathrm{~min}$ using a TE-102 Turratec equipment (Tecnal, Brazil). The dispersion was then centrifuged at $3,500 \times \mathrm{g}$ for $5 \mathrm{~min}$ and a $12-\mathrm{ml}$ aliquot of the supernatant transferred to a previously weighed Petridish and dried in an oven at $105^{\circ} \mathrm{C}$ (MA 033, Marconi, Brazil) to constant weight.

\section{Experimental design}

A $2^{3}$ complete factorial design with two repetitions, giving a total of 16 treatments, was used to characterize the foam mat drying process and determine the factors influencing the responses of the color parameters $\left(L^{*}, a^{*}, b^{*}, C^{*}\right.$, and $\left.h^{*}\right)$, carotenoid retention and powder solubility. Each treatment corresponded to a combination of the levels of the factors, that is: drying temperature $x_{1}$, EMB concentration $x_{2}$, and ALB concentration $x_{3}$. All the factors were investigated at two levels, the codified maximum level being equal to +1 and the minimum to -1 . Table 1 shows the codified values of the factors and the order the experiments were performed.

The regression model was fitted to describe each response variable, according to the general form of the first-order model described by Montgomery ${ }^{[30]}$ :

$$
\begin{aligned}
y_{i}= & \beta_{0}+\beta_{1} x_{1}+\beta_{2} x_{2}+\beta_{3} x_{3}+\beta_{12} x_{1} x_{2} \\
& +\beta_{13} x_{1} x_{3}+\beta_{23} x_{2} x_{3}+\beta_{123} x_{1} x_{2} x_{3}+\varepsilon_{i}
\end{aligned}
$$

In Eq. (9), $y$ identifies the response variable, where $i=1,2,3,4,5,6,7$, or more specifically $y_{1}$ represents the lightness $\left(L^{*}\right), y_{2}$ the parameter $a^{*}, y_{3}$ the parameter $b^{*}, y_{4}$ the chroma $\left(C^{*}\right), y_{5}$ the hue angle $\left(h^{*}\right), y_{6}$ the percent carotenoid retention, $y_{7}$ the solubility, and $y_{8}$ the diffusion coefficient of water. $\beta_{0}, \beta_{1}, \beta_{2}, \beta_{3}, \beta_{12}, \beta_{13}, \beta_{23}, \beta_{123}$, are the model parameters (regression coefficient) whose values are to be determined, $x_{1}$ is a variable that represents the factor temperature, $x_{2}$ is a variable that represents the factor EMB concentration, and $x_{3}$ is a variable that represents the factor ALB concentration. Finally $x_{1} x_{2}, x_{1} x_{3}, x_{2} x_{3}$ and $x_{1} x_{2} x_{3}$ represent the interactions and $\varepsilon_{i}$ is the random error term.

\section{Statistical analyses}

Analyses of variance were performed to evaluate the influence of the response variables of interest, considering a significance level of $5 \%$. The results were obtained using the Minitab $16{ }^{\circledR}$ program. Fick's Law mathematical model was fitted to the experimental drying curves using the program Statistica 7.0. The coefficient of determination $\left(R^{2}\right)$ and the chi-squared statistic $\chi^{2}$ were used to evaluate the capacity of the mathematical model to represent drying, and the best fit was identified for high $R^{2}$ values and low $\chi^{2}$ values.

\section{Results and discussion}

\section{Effects of temperature and foaming agent concentration}

The mango pulp used in all the trials was characterized with respect to its moisture content, carotenoid content, ${ }^{\circ} \mathrm{Brix}, \mathrm{pH}$, and color parameters (Table 2).

Table 3 shows the results of the responses evaluated during the mango pulp foam mat drying process, determining the color parameters $L^{*}, a^{*}, b^{*}, C^{*}$ and $h^{*}$, carotenoid retention and powder solubility. Table 4 shows the results obtained in the significance tests associated with each term in the model fitted for the different response variables, and Table 5 shows the estimates for the regression coefficients for each term in the model.

Lightness $\left(L^{*}\right)$ was significantly affected by the presence of the foaming agents and by the interaction between them (Table 4) but not by the temperature. As shown by coefficient $\beta_{2}$ (Table 5), an increase in 
Table 2. Means and standard deviation for each physicochemical characteristics of the mango pulp.

\begin{tabular}{lr}
\hline Parameter & \multicolumn{1}{c}{ Value } \\
\hline Moisture content $\left(\mathrm{kg}\right.$ water $\cdot 100 \mathrm{~kg}^{-1}$ total) & $85.66 \pm 0.11$ \\
Soluble solids ('Brix) & $13.81 \pm 0.05$ \\
$\mathrm{pH}$ & $4.01 \pm 0.06$ \\
Carotenoids $\left(\mu \mathrm{g} \mathrm{g}^{-1}\right.$ total) & $16.90 \pm 0.43$ \\
$L^{*}$ & $58.91 \pm 0.08$ \\
$a^{*}$ & $11.93 \pm 0.35$ \\
Color parameters & \\
$b^{*}$ & $71.78 \pm 0.57$ \\
$C^{*}$ & $59.33 \pm 1.32$ \\
$h^{*}$ & $80.57 \pm 0.53$ \\
\hline
\end{tabular}

the EMB concentration resulted in a pronounced tendency for an increase in the value for lightness $\left(\mathrm{L}^{*}\right)$. Similar behavior was also shown by coefficient $\beta_{3}$ for an increase in the ALB concentration (Table 5). However, the interaction between these two factors resulted in a negative effect on lightness, although the coefficient, $\beta_{23}$, whose value in the module was lower than that of $\beta_{1}$ and of $\beta_{2}$, exerted a smaller weight on this response, such that the values for $L^{*}$ were still very high when a mixture of the two agents was present (Table 3 ). The $L^{*}$ value increasing was attributed to the incorporation of the air into the mango pulp during the foaming process, which increases with the addition of foaming agents. ${ }^{[16]}$ Other authors have also found high values for lightness in powders obtained by foam mat drying. Falade et al. ${ }^{[20]}$ obtained a value for $L^{*}$ of 76.76 in cowpea powder containing glyceryl monostearate, whereas Karim and Wai ${ }^{[31]}$ obtained values of 78.4 for starfruit powder obtained from a mixture of the pulp with methylcellulose as the foaming agent. High values for lightness (70) were also reported by Chauhan and Patil $^{[32]}$ who spray dried mango pulp with milk.
The parameter $a^{*}$ was affected by the EMB concentration, the ALB concentration, and by the interactions between the temperature and EMB concentration and between the temperature and ALB concentration (Table 4). Although the rise in temperature caused a slight increase in this response, the effect of the foaming agents was negative and more intense than that of temperature (Table 5). From the experimental results, it is possible to conclude that the addition of foaming agents tends to reduce $a^{*}$ value, indicating that they could reduce the nonenzymatic browning reactions. ${ }^{[33]}$ The parameter $b^{*}$ is one of the most important characteristics in terms of mango color, since it indicates the intensity of the yellow color. During processing, $b^{*}$ was significantly affected by the interaction between the agents EMB-ALB and by the ALB concentration (Table 4), although the temperature alone did not exert a significant effect on $b^{*}$. An increase in the concentration of EMB, ALB, or of both implied in a slight decrease in the parameter $b^{*}$ in the dehydrated powder, even at a higher drying temperature $\left(80^{\circ} \mathrm{C}\right)$, since this parameter was positively affected by the temperature only through the interaction factor $\beta_{123}$ (Table 5). Similar results were obtained by Gupta and Alam, ${ }^{[34]}$ which reported that the incorporation of egg albumen and methyl cellulose as foaming agents in grape concentrate decreased the parameters $a^{*}$ and $b^{*}$.

The parameter $h^{*}$, which represents the tonality of the powders, was affected by the three variables involved in the process, negatively by temperature but positively by the EMB and ALB concentrations, and also by the interactions between the temperature and EMB concentration and between the temperature and ALB

Table 3. Descriptive statistics for the color parameters, carotene retention, solubility, and diffusion coefficients related to the $2^{3}$ factorial experimental design for mango powders.

\begin{tabular}{|c|c|c|c|c|c|c|c|c|}
\hline \multirow{2}{*}{$\begin{array}{l}\text { Treatments } \\
\text { (randomized trial) }\end{array}$} & \multicolumn{7}{|c|}{ Responses } & \multirow{2}{*}{$\begin{array}{c}D_{\text {eff }} \times 10^{10} \\
\left(\mathrm{~m}^{2} \cdot \mathrm{s}^{-1}\right)\left[R^{2}\right]\end{array}$} \\
\hline & $L^{*}$ & $a^{*}$ & $b^{*}$ & $h^{*}$ & $C^{*}$ & Ret (\%) & $\mathrm{S}$ & \\
\hline \multicolumn{9}{|l|}{$60^{\circ} \mathrm{C}$} \\
\hline Pulp (7) & $44.90 \pm 1.27$ & $6.52 \pm 1.08$ & $39.68 \pm 3.81$ & $80.70 \pm 0.92$ & $45.38 \pm 1.18$ & $36.53 \pm 0.99$ & $88.90 \pm 2.43$ & $2.41[0.995]$ \\
\hline Pulp (10) & $45.30 \pm 0.63$ & $6.45 \pm 0.21$ & $42.86 \pm 1.26$ & $81.43 \pm 0.40$ & $45.76 \pm 0.65$ & $45.42 \pm 5.09$ & $86.23 \pm 1.95$ & 2.15 [0.995] \\
\hline EMB (3) & $82.47 \pm 0.26$ & $5.01 \pm 0.20$ & $52.25 \pm 0.89$ & $84.53 \pm 0.12$ & $52.48 \pm 0.90$ & $67.55 \pm 0.03$ & $91.03 \pm 0.72$ & $2.49[0.987]$ \\
\hline EMB (4) & $83.95 \pm 0.31$ & $4.17 \pm 0.05$ & $47.21 \pm 0.19$ & $84.95 \pm 0.05$ & $47.39 \pm 0.19$ & $61.18 \pm 5.00$ & $90.52 \pm 2.39$ & $2.91[0.992]$ \\
\hline ALB (9) & $79.65 \pm 0.22$ & $6.76 \pm 0.26$ & $43.76 \pm 1.62$ & $81.34 \pm 0.06$ & $44.27 \pm 1.64$ & $53.75 \pm 0.73$ & $88.39 \pm 0.49$ & $3.66[0.998]$ \\
\hline ALB (13) & $77.98 \pm 0.23$ & $6.72 \pm 0.11$ & $45.43 \pm 0.84$ & $81.63 \pm 0.04$ & $45.92 \pm 0.85$ & $57.72 \pm 10.78$ & $84.32 \pm 1.38$ & $3.44[0.997]$ \\
\hline EMB-ALB (1) & $84.76 \pm 0.13$ & $2.91 \pm 0.09$ & $36.32 \pm 0.76$ & $85.42 \pm 0.06$ & $36.43 \pm 0.76$ & $72.84 \pm 6.91$ & $82.79 \pm 0.48$ & $2.82[0.998]$ \\
\hline EMB-ALB (14) & $83.05 \pm 0.04$ & $3.40 \pm 0.07$ & $40.19 \pm 0.18$ & $85.15 \pm 0.08$ & $40.33 \pm 0.18$ & $78.60 \pm 2.41$ & $88.07 \pm 0.69$ & $2.52[0.996]$ \\
\hline \multicolumn{9}{|l|}{$80^{\circ} \mathrm{C}$} \\
\hline Pulp (2) & $44.61 \pm 0.70$ & $14.00 \pm 1.74$ & $46.77 \pm 3.11$ & $73.39 \pm 0.96$ & $46.78 \pm 1.13$ & $42.91 \pm 4.42$ & $85.07 \pm 0.56$ & 3.47 [0.994] \\
\hline Pulp (8) & $52.33 \pm 0.33$ & $11.19 \pm 0.31$ & $46.95 \pm 1.11$ & $76.59 \pm 0.12$ & $53.51 \pm 0.29$ & $50.25 \pm 4.61$ & $83.87 \pm 0.20$ & 3.05 [0.996] \\
\hline EMB (12) & $80.58 \pm 0.36$ & $6.65 \pm 0.18$ & $50.62 \pm 0.44$ & $82.51 \pm 0.24$ & $51.01 \pm 0.42$ & $59.91 \pm 0.29$ & $89.54 \pm 0.62$ & $5.17[0.992]$ \\
\hline EMB (16) & $81.87 \pm 0.43$ & $5.65 \pm 0.28$ & $49.64 \pm 1.93$ & $83.51 \pm 0.08$ & $49.96 \pm 1.95$ & $61.01 \pm 3.01$ & $92.51 \pm 0.97$ & 5.49 [0.996] \\
\hline ALB (11) & $78.81 \pm 0.24$ & $6.76 \pm 0.11$ & $46.56 \pm 1.57$ & $81.73 \pm 0.21$ & $47.05 \pm 1.57$ & $83.94 \pm 18.74$ & $84.45 \pm 1.10$ & $5.17[0.995]$ \\
\hline ALB (15) & $77.60 \pm 0.43$ & $6.61 \pm 0.16$ & $43.29 \pm 0.99$ & $81.26 \pm 0.18$ & $43.76 \pm 0.99$ & $94.45 \pm 5.57$ & $85.90 \pm 0.55$ & $4.96[0.995]$ \\
\hline EMB-ALB (5) & $85.18 \pm 0.16$ & $2.48 \pm 0.02$ & $35.55 \pm 0.20$ & $86.01 \pm 0.02$ & $35.63 \pm 0.20$ & $81.24 \pm 9.25$ & $88.84 \pm 0.47$ & 6.12 [0.997] \\
\hline EMB-ALB (6) & $83.66 \pm 0.26$ & $3.54 \pm 0.04$ & $38.05 \pm 0.61$ & $84.68 \pm 0.04$ & $38.21 \pm 0.61$ & $75.88 \pm 1.53$ & $82.70 \pm 2.26$ & 5.34 [0.995] \\
\hline
\end{tabular}

Pulp, pure mango pulp; ALB, mango powder with albumin (10 kg ALB $\cdot 100 \mathrm{~kg}^{-1}$ pulp); EMB, mango powder with emulsifier blend $\left(2 \mathrm{~kg} E M B \cdot 100 \mathrm{~kg}{ }^{-1}\right.$ pulp); EMB-ALB, mango powder with albumin (10 kg ALB $\cdot 100 \mathrm{~kg}^{-1}$ pulp) and emulsifier blend $\left(2 \mathrm{~kg} \mathrm{EMB} \cdot 100 \mathrm{~kg}^{-1}\right.$ pulp). 
Table 4. Results of the analysis of variance for the influence of the factors on the responses: color parameters, carotene retention, powder solubility, and effective diffusion coefficients.

\begin{tabular}{|c|c|c|c|c|c|c|c|c|c|c|c|c|c|c|c|c|c|}
\hline \multirow{2}{*}{$\begin{array}{l}\text { Source of } \\
\text { variation }\end{array}$} & \multirow[b]{2}{*}{ Df } & \multicolumn{2}{|c|}{$L^{*}$} & \multicolumn{2}{|c|}{$a^{*}$} & \multicolumn{2}{|c|}{$b^{*}$} & \multicolumn{2}{|c|}{$h^{*}$} & \multicolumn{2}{|c|}{$C^{*}$} & \multicolumn{2}{|c|}{ Ret (\%) } & \multicolumn{2}{|c|}{ S (\%) } & \multicolumn{2}{|c|}{$D_{\text {eff }} \times 10^{10}\left(\mathrm{~m}^{2} \cdot \mathrm{s}^{-1}\right)$} \\
\hline & & SQ & $P$-value & SQ & $P$-value & SQ & $P$-value & SQ & $P$-value & SQ & $P$-value & SQ & $P$-value & SQ & $P$-value & SQ & $P$-value \\
\hline$x_{1}$ & 1 & 0.42 & 0.770 & 13.93 & 0.002 & 5.91 & 0.282 & 14.96 & 0.003 & 21.66 & 0.320 & 371.57 & 0.003 & 3.412 & 0.485 & 16.734 & 0.000 \\
\hline$x_{2}$ & 1 & $1,678.60$ & 0.000 & 60.90 & 0.000 & 1.87 & 0.534 & 93.59 & 0.000 & 32.15 & 0.233 & 527.63 & 0.001 & 22.223 & 0.090 & 1.2854 & 0.004 \\
\hline$x_{3}$ & 1 & $1,133.44$ & 0.000 & 26.17 & 0.000 & 137.13 & 0.001 & 24.06 & 0.001 & 0.21 & 0.918 & $1,908.95$ & 0.000 & 30.881 & 0.590 & 2.9866 & 0.000 \\
\hline$x_{1} x_{2}$ & 1 & 4.47 & 0.352 & 5.39 & 0.023 & 12.14 & 0.137 & 4.85 & 0.047 & 19.58 & 0.343 & 389.01 & 0.003 & 5.920 & 0.363 & 2.5544 & 0.001 \\
\hline$x_{1} x_{3}$ & 1 & 0.55 & 0.738 & 15.51 & 0.001 & 12.61 & 0.131 & 15.49 & 0.003 & 55.15 & 0.129 & 289.90 & 0.006 & 1.004 & 0.702 & 0.2351 & 0.130 \\
\hline$x_{2} x_{3}$ & 1 & 886.90 & 0.000 & 0.30 & 0.528 & 171.4 & 0.000 & 4.11 & 0.063 & 14.83 & 0.406 & 185.30 & 0.018 & 25.428 & 0.081 & 1.8312 & 0.002 \\
\hline$x_{1} x_{2} x_{3}$ & 1 & 10.51 & 0.168 & 4.97 & 0.028 & 2.88 & 0.445 & 4.63 & 0.051 & 0.28 & 0.906 & 118.82 & 0.046 & 0.837 & 0.726 & 0.0026 & 0.863 \\
\hline Pure error & 8 & 36.52 & & 5.49 & & 35.62 & & 7.04 & & 154.31 & & 170.07 & & 50.940 & & 0.6590 & \\
\hline$R^{2}$ & & 0.99 & & 0.95 & & 0.91 & & 0.96 & & 0.48 & & 0.96 & & 0.64 & & 0.97 & \\
\hline Adjusted $R^{2}$ & & 0.98 & & 0.92 & & 0.82 & & 0.92 & & 0.03 & & 0.92 & & 0.32 & & & 0.95 \\
\hline
\end{tabular}

df, degrees of freedom.

concentration (Table 4). This signified that an increase in concentration of the foaming agents tended to increase $h^{*}$, making the powders more yellow rather than more orange, even with decreases in the values for $b^{*}$ and $a^{*}$, since the parameter $h^{*}$ results from a combination of the two (Eq. 7). For its part, the temperature affected this parameter negatively, which was more evident in the pulp without additives, whose yellow tonality became more orange at $80^{\circ} \mathrm{C}$ due to the decrease in the value of $h^{*}$ (Table 3).

On the other hand, the parameter chroma was not significantly affected by the factors analyzed (Table 4 ). An analysis of how the color is perceived in terms of ohue and chroma is of great importance, since they indicate the tonality of the mango powders and how bright its color is after drying under the different process conditions. From the results obtained (Table 3), it can be seen that the values found for ${ }^{\circ}$ hue in the powders prepared with additives were always close to $80^{\circ}$, indicating a yellowy-orange tone. In addition, the values for chroma presented values between 36 and 50 units, indicating less saturation and consequently a less intense color. Caparino et al. $^{[29]}$ reported data for spray-dried mango powders with added maltodextrin, showing values for ${ }^{\circ}$ hue around 80 and for chroma around 40 , close to the values obtained in the present study, signifying that the different additives produced powders of similar color. However it must be mentioned that the powders with added EMB always presented more vivid colors than those with added ALB-EMB.

\section{Percent total carotenoid retention}

With respect to the percent total carotenoid retention, this response was significantly affected by all the factors, including the interactions (Table 4). The most significant effect was due to the ALB concentration, which caused increased retention with increasing concentration. Similarly increments in the EMB concentration, in the temperature and in the temperature-ALB concentration interaction, all exerted positive effects on retention, while the temperature-EMB concentration and ALB concentration-EMB concentration interactions presented negative effects on this response. On comparing the product obtained from the pulp dried without additives with those dried with foaming agents, the latter presented retentions equal or higher than 53\%, showing that their addition improved carotenoid retention. These results suggest that the addition of ALB, EMB, or EMB-ALB provides some protection against degradation of the carotenoids, resulting in higher retention than without the foaming agents. The greatest percent retention of $88.9 \%$ was obtained with $\mathrm{ALB}$ at $80^{\circ} \mathrm{C}$. High carotenoid retention was reported by Pott et al. ${ }^{[35]}$ on drying mango slices for short periods of $3.5 \mathrm{~h}$, obtaining retentions of trans- $\beta$-carotene in the range from $70 \%$ to $93 \%$. In general, better percent

Table 5. Regression coefficients for the fitted model according to Eq. (9) for the responses to the mango powder parameters: Responses for the color parameters, carotenoid retention, and coefficient of diffusion.

\begin{tabular}{|c|c|c|c|c|c|c|}
\hline & $L^{*}$ & $a^{*}$ & $b^{*}$ & $h^{*}$ & Ret (\%) & $D_{\text {eff }} \times 10^{10}\left(\mathrm{~m}^{2} \cdot \mathrm{s}^{-1}\right)$ \\
\hline$\beta_{0}$ & 72.918 & 6.177 & 44.068 & 82.1772 & 63.882 & 3.8234 \\
\hline$\beta_{1}$ & $0.162^{*}$ & 0.933 & $0.608^{*}$ & -0.9669 & 4.819 & 1.0227 \\
\hline$\beta_{2}$ & 10.270 & -1.951 & -0.343 & 2.4186 & 5.743 & 0.2834 \\
\hline$\beta_{3}$ & 8.417 & -1.279 & -2.928 & 1.2264 & 10.923 & 0.4320 \\
\hline$\beta_{12}$ & $-0.528^{*}$ & -0.581 & $-0.871^{*}$ & 0.5503 & -4.931 & 0.3996 \\
\hline$\beta_{13}$ & $-0.185^{*}$ & -0.985 & $-0.888^{*}$ & 0.9838 & 4.257 & $0.1212^{*}$ \\
\hline$\beta_{23}$ & -7.445 & $0.137^{*}$ & -3.274 & $-0.5069^{*}$ & -3.403 & -0.3383 \\
\hline$\beta_{123}$ & 0.811 & 0.557 & 0.424 & -0.5380 & -2.725 & $-0.0128^{*}$ \\
\hline
\end{tabular}

*Nonsignificant term. 
carotenoid retentions were obtained at the higher temperature in the present study. This was due to the fact that at the higher temperature, the lipoxygenases, responsible for the enzymatic degradation of the carotenoids, showed a minimal rate of activity. ${ }^{[36]}$ In addition, all the drying times were short, which could have contributed to the maintenance of these compounds due to the rapid decrease in moisture content and reduced time of exposure to oxygen. Sramek et al. ${ }^{[37]}$ when drying tomato paste foamed with whey protein isolate or egg white, found that $\beta$-carotene content did not show significant differences for drying temperatures between 50 and $70^{\circ} \mathrm{C}$, being that its minimum retention was $81 \%$. The relation between the drying time and carotenoid retention has been described by Auisakchaiyoung and Rojanakorn ${ }^{[15]}$ for dried Gac fruit (M. cochinchinensis) aril. The authors found the greatest degradation of $\beta$-carotene for the lengthy dryings, which, in turn, were dependent on the foam thickness and the drying temperature.

\section{Solubility}

The solubility of the mango powders was not significantly affected by the ALB concentration, EMB concentration (Table 4), which could be attributed to the influence of the sugars on the solubility (S), since their amounts are the highest in comparison to the total solutes of the powders. Even though the solubility was not significantly affected by the foam agents, it can be observed that the EMB powders were more soluble than those obtained with ALB or EMB-ALB (Table 3). These differences could have been due to the nature of the emulsifiers used, since they have the capacity to improve the solubility due to the lipophilic-hydrophilic balance of the molecule. ${ }^{[38]}$ Also, the drying temperature did not significantly affect the solubility (Table 4). This behavior has also been reported by Mishra et al. ${ }^{[39]}$ for the solubility of amla (Emblica officinalis) juice powder and by Franco et al. ${ }^{[22]}$ for the yacon juice powder. The solubility of the present powders was similar to that of powders obtained by Caparino et al. ${ }^{[29]}$ by freeze-drying Philippine mangoes of the variety "Carabao" $\left(89.70 \mathrm{~kg} 100 \mathrm{~kg}^{-1}\right)$, but lower than the values obtained for the same mango variety using a rotary drum and a spray drier (the latter with the addition of maltodextrin), which presented values of 94.38 and $95.31 \mathrm{~kg} 100 \mathrm{~kg}^{-1}$, respectively. Conversely, in the present study, the solubility values were higher than those reported by Wilson et al. ${ }^{[40]}$ for mango juice powder obtained by foam mat drying using albumin as foaming agent, whose values were between 51.83 and $66.65 \mathrm{~kg} \cdot 100 \mathrm{~kg}^{-1}$.

\section{Drying kinetics}

The foams produced with EMB, ALB, and EMB-ALB and the fresh pulp presented mean initial water contents of $85.67 \pm 0.22 \mathrm{~kg} \cdot 100 \mathrm{~kg}^{-1}$ total mass, $78.61 \pm$ $0.25 \mathrm{~kg} \cdot 100 \mathrm{~kg}^{-1}, 78.70 \pm 0.23 \mathrm{~kg} \cdot 100 \mathrm{~kg}^{-1}$, and $85.87 \pm$ $0.57 \mathrm{~kg} \cdot 100 \mathrm{~kg}^{-1}$, respectively, values which were reduced by drying to moisture contents in the range from 3.33 to $1.52 \mathrm{~kg} \cdot 100 \mathrm{~kg}^{-1}$ in powders containing additives, and from 8.44 to $6.55 \mathrm{~kg} \cdot 100 \mathrm{~kg}^{-1}$ in the powder without additives (Table 2). The water content differences between the powders obtained from foamed and nonfoamed mango pulp were related to the foam structure, which increases the evaporation surface, improving the process of moisture removal from the product. ${ }^{[16,41,42]}$ Hence, the powders containing foaming agents demonstrated the potential of this technology, since these low moistures should confer stability and the properties required for fruit pulp powders. Similar moisture content values were found for foam mat-dried products, such as pineapple pulp powder ${ }^{[6]}\left(3-3.5 \mathrm{~kg} \cdot 100 \mathrm{~kg}^{-1}\right.$ total mass), muskmelon pulp powder ${ }^{[16]}\left(2.69-2.2 \mathrm{~kg} \cdot 100 \mathrm{~kg}^{-1}\right.$ total mass), and mango pulp powder with egg white ${ }^{[43]}$ (1.12$3.05 \mathrm{~kg} \cdot 100 \mathrm{~kg}^{-1}$ total mass). As shown in Table 6, the water contents of the ALB and EMB-ALB powders showed differences according to the temperature used $\left(80\right.$ or $60^{\circ} \mathrm{C}$ ), whereas the EMB powders showed similar moisture contents for the two temperatures.

Table 6. Water content and water activity (measured at $25^{\circ} \mathrm{C}$ ) of the mango powders obtained in the different treatments.

\begin{tabular}{lcccc}
\hline Formulation & Drying temperature $\left({ }^{\circ} \mathrm{C}\right)$ & Relative humidity RH $(\%)$ & Water content $\left(\mathrm{kg} \cdot 100 \mathrm{~kg}^{-1}\right.$ total mass) & $a_{w}$ (at $\left.25^{\circ} \mathrm{C}\right)$ \\
\hline Pulp & 60 & $9.24 \pm 0.47$ & $8.44 \pm 0.32^{\mathrm{a}}$ & $0.46 \pm 0.04^{\mathrm{a}}$ \\
& 80 & $5.29 \pm 0.23$ & $6.55 \pm 0.69^{\mathrm{b}}$ & $0.38 \pm 0.03^{\mathrm{b}}$ \\
ALB & 60 & $10.69 \pm 0.50$ & $2.95 \pm 0.97^{\mathrm{c}}$ & $0.27 \pm 0.01^{\mathrm{c}}$ \\
& 80 & $5.15 \pm 0.20$ & $1.55 \pm 0.17^{\mathrm{d}}$ & $0.15 \pm 0.02^{\mathrm{d}}$ \\
EMB & 60 & $9.74 \pm 0.44$ & $3.33 \pm 0.34^{\mathrm{c}}$ & $0.21 \pm 0.01^{\mathrm{e}}$ \\
& 80 & $5.59 \pm 0.19$ & $2.87 \pm 0.25^{\mathrm{c}}$ & $0.20 \pm 0.01^{\mathrm{e}}$ \\
EMB-ALB & 60 & $9.48 \pm 0.41$ & $3.43 \pm 0.23^{\mathrm{c}}$ & $0.27 \pm 0.03^{\mathrm{c}}$ \\
& 80 & $4.90 \pm 0.16$ & $1.32 \pm 0.20^{\mathrm{d}}$ & $0.13 \pm 0.02^{\mathrm{d}}$ \\
\hline
\end{tabular}

Means with the same letter in the same column indicate no significant difference by the Tukey test $(P<0.05)$. Pulp, pure mango pulp; ALB, mango powder with albumin (10 kg $100 \mathrm{~kg}^{-1}$ pulp); EMB, mango powder with emulsifier blend $\left(2 \mathrm{~kg} \cdot 100 \mathrm{~kg}^{-1}\right.$ pulp); EMB-ALB, mango powder with albumin (10 kg $100 \mathrm{~kg}^{-1}$ pulp) and emulsifier blend $\left(2 \mathrm{~kg} 100 \mathrm{~kg}^{-1}\right.$ pulp). Means of two experimental trials \pm standard deviation. 
The water activities of the mango powders with ALB, $\mathrm{EMB}$, and EMB-ALB were between 0.27 and 0.13 , whose values are sufficiently low to prevent growth of microorganisms. In addition, one must mention that low $a_{w}$ values contribute to pigment and/or color stability, since in the $a_{w}$ range between 0.1 and 0.4 , auto-oxidation reactions are minimal due to inactivation of the lipoxygenases. ${ }^{[4]}$ It should be noted that the powders with ALB and EMB-ALB showed low values for water activity, in the range between 0.15 and 0.13 , when dried at $80^{\circ} \mathrm{C}$. Similar values of $\mathrm{a}_{\mathrm{w}}$ were reported for the powders obtained from yacon juice foamed with albumin and dried at 50,60 , and $70^{\circ} \mathrm{C}$, ${ }^{[22]}$ Gac fruit foamed with methylcellulose and dried at 60 , 70 , and $80^{\circ} \mathrm{C}^{[15]}$ and shrimp powder foamed with xanthan gum and dried at $45,60,75$, and $90^{\circ} \mathrm{C}^{[21]}$

Figure 1a shows the moisture content of the foams as a function of time, representing the drying kinetics at $60^{\circ} \mathrm{C}$ of the mango pulp foams containing EMB, ALB, EMB-ALB, and without the addition of foaming agents. An evaluation of the drying times at $60^{\circ} \mathrm{C}$ showed that the foams prepared with EMB and EMB-ALB exhibited
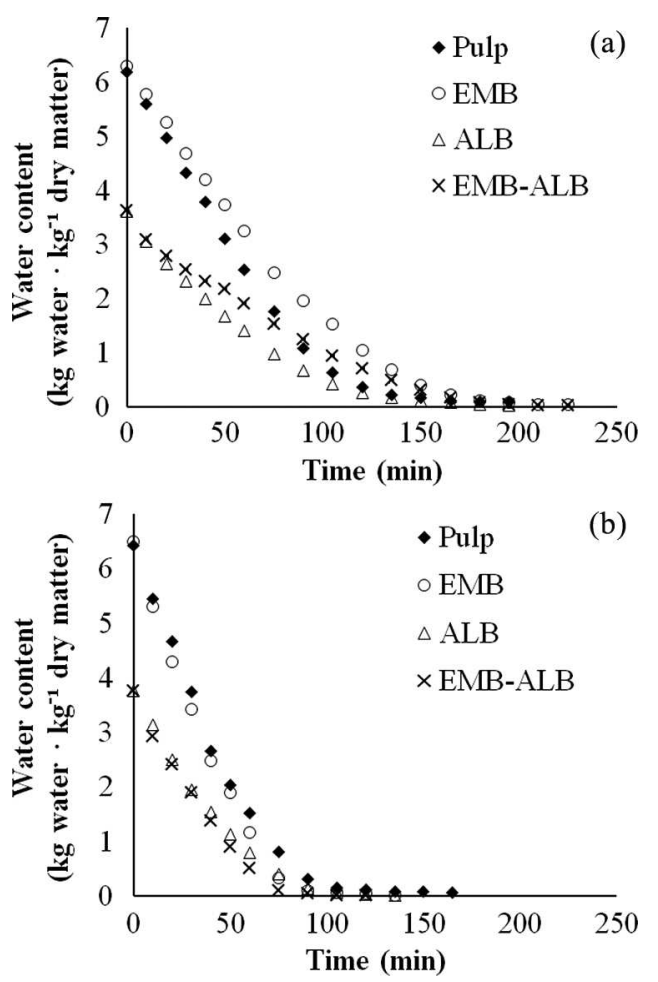

Figure 1. Drying kinetics of the pure mango pulp, and of the foams with EMB (2 kg $100 \mathrm{~kg}^{-1}$ pulp), with ALB (10 kg $100 \mathrm{~kg}^{-1}$ pulp), and with EMB (2 kg $100 \mathrm{~kg}^{-1}$ pulp) plus ALB (10 kg $100 \mathrm{~kg}^{-1}$ pulp at $60^{\circ} \mathrm{C}$ (a) and $80^{\circ} \mathrm{C}$ (b). Note: $A L B$, mango powder with albumin (10 kg $100 \mathrm{~kg}^{-1}$ pulp); EMB, mango powder with emulsifier blend ( $2 \mathrm{~kg} \cdot 100 \mathrm{~kg}^{-1}$ pulp); EMB-ALB, mango powder with albumin (10 kg $100 \mathrm{~kg}^{-1}$ pulp) and emulsifier blend ( $2 \mathrm{~kg} 100 \mathrm{~kg}^{-1}$ pulp). a tendency for longer drying times than the foams produced with ALB or the fresh pulp. At $60^{\circ} \mathrm{C}$, the foam with ALB reached low moisture contents quicker than the other foams and also than the pulp without additives. At $80^{\circ} \mathrm{C}$, the differences between the drying times required to reach lower moisture contents were less pronounced (Fig. 1b), although the equilibrium moisture contents showed differences due to the water sorption properties of the different components and to their proportions in the foam compositions. Table 6 shows that the mango pulp without the addition of any additive retained the largest amount of moisture, this being associated with the elevated sugar content in relation to the total dry matter when compared to formulations with foaming agents, since the water interact more with the sugars ${ }^{[45]}$ than with the proteins. ${ }^{[46]}$ When dried at $60^{\circ} \mathrm{C}$, the equilibrium moisture content reached for the pulp was $8.44 \pm 0.32 \mathrm{~kg}$ water $\cdot 100 \mathrm{~kg}^{-1}$ total mass (Table 6), significantly different from the equilibrium moisture content attained with EMB, with a value of $3.33 \pm 0.22 \mathrm{~kg}$ water $\cdot 100 \mathrm{~kg}^{-1}$ total mass. However the drying of the pulp without additives showed greater drying rates than the foams with EMB (Fig. 1a). Since the drying rate of the pulp was higher at the start of drying, this suggests the formation of hardened crusts on the surface of the dehydrated pulp at $60^{\circ} \mathrm{C}$, making the loss of further water difficult in the later stages of drying.

However, one must consider that if, on one hand, migration of the water inside the foam to the surface is facilitated by the porous structure, on the other hand, the emulsifier agents have the role of retaining water. Consequently, the drying curves are the result of these two factors, which exert opposite effects on the drying rates. It is possible that at $60^{\circ} \mathrm{C}$ the effect of water retention by the emulsifiers was more pronounced than the effect of porosity, justifying the greater drying rate of the pulp.

The behavior of the drying curve at $80^{\circ} \mathrm{C}$ shows a tendency for a greater moisture loss than that obtained at $60^{\circ} \mathrm{C}$, which may be explained by an increase in molecular mobility thereby improving the removal of water from the foams and consequently reducing the drying times. ${ }^{[17]}$ On comparing the EMB foams with the fresh pulp, it can be seen that at this high temperature, the curves showed similar moisture loss behaviors, the drying rate of the foam with EMB being slightly superior to that of the pulp, indicating an increase in the efficiency of the foam mat. Once again, the equilibrium moisture content reached by the fresh pulp was high, equal to $6.55 \pm 0.69 \mathrm{~kg}$ water $\cdot 100 \mathrm{~kg}^{-1}$ total mass (Table 5), significantly higher than that obtained for the EMB foam, which was $2.87 \pm 0.25 \mathrm{~kg}$ water $\cdot 100 \mathrm{~kg}^{-1}$ 
total mass. This could be explained by the greater water retention due to the greater proportion of sugars in the total dry mass of the fruit pulp powder. With respect to the emulsifier agents, the drying kinetics at 60 and $80^{\circ} \mathrm{C}$ always showed superior drying rates for the foams with EMB than for the foams with ALB or EMB-ALB. This could be a result of the lower density obtained in the EMB foams, which improved the migration velocity of the water inside the product.

During foam mat drying, it was considered that the movement of moisture into nonfoamed and foamed mango pulp was by liquid diffusion. Thus, the drying kinetics was described according to Fick's law of diffusion $^{[22]}$ and the curves are represented in Fig. 1. The effective diffusion coefficients are shown in Table 3 with their corresponding coefficients of determination $R^{2}$ (above 0.98 ).

Other authors have modeled the drying kinetics of foams using the diffusion equation, for example, Thuwapanichayanan et al. ${ }^{[4]}$ for banana foam and Djaeni et al. ${ }^{[48]}$ for carrageenan foam. The effective diffusion coefficients for the water in the fresh mango pulp and mango foams were calculated as from the analytical solution of Fick's equation (Eq. 5). This was fitted to the experimental data of two trials using the Statistica 7.0 software, with seven terms, a number which enables one to obtain convergence of the diffusivity values. Figures 2 and 3 compare the experimental data with the results calculated according to Eq. (5), for drying at 60 and $80^{\circ} \mathrm{C}$, respectively. The $D_{\text {eff }}$ was affected by the temperature, concentrations of EMB and ALB, and also by the interactions between the temperature and EMB concentration and between the concentrations of
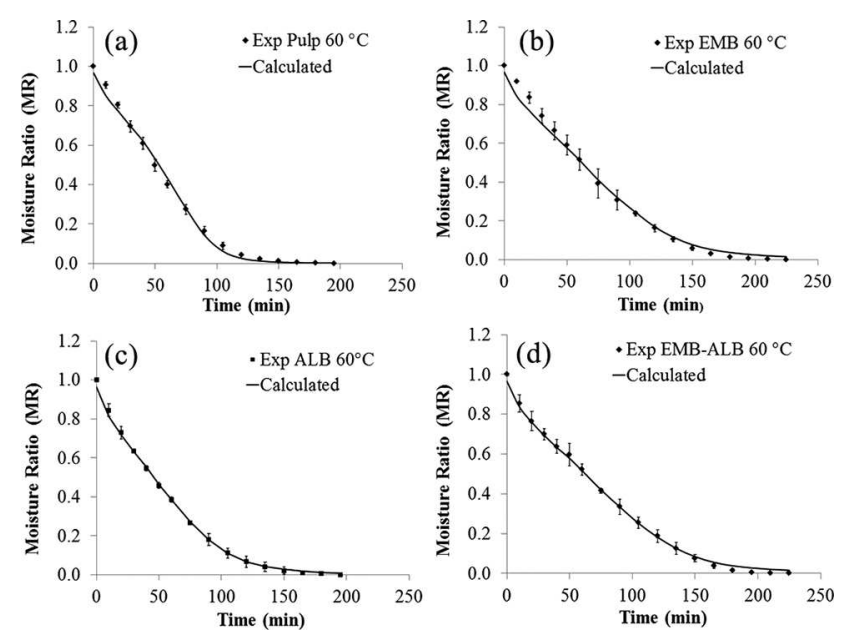

Figure 2. Ratios of the experimental to the predicted moisture contents at $60^{\circ} \mathrm{C}$ for (a) mango pulp, (b) foam with EMB, (c) foam with $A L B$, and (d) foam with EMB-ALB. The bars represent the standard deviation.
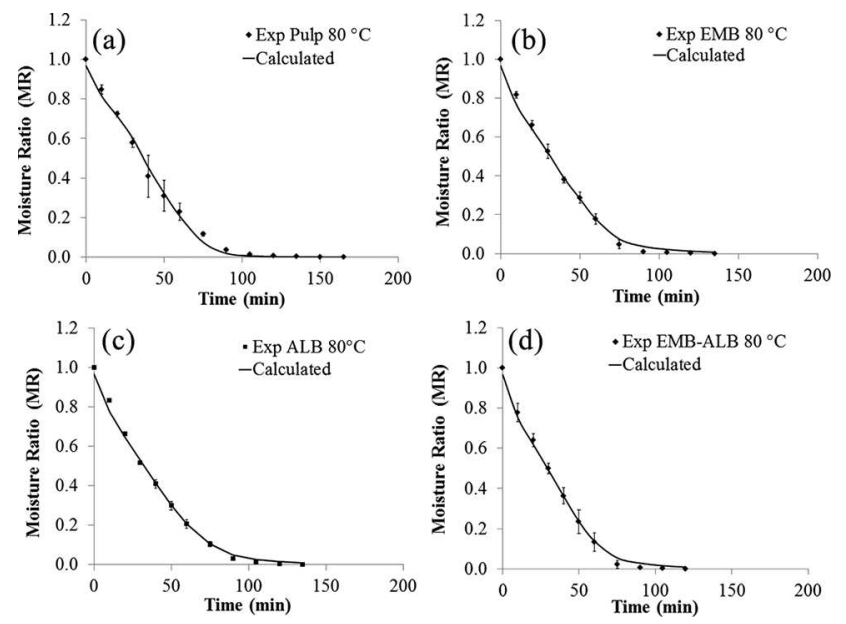

Figure 3. Ratios of the experimental to the predicted moisture contents at $80^{\circ} \mathrm{C}$ for (a) mango pulp, (b) foam with EMB, (c) foam with $A L B$, and (d) foam with EMB-ALB. The bars represent the standard deviation.

EMB and ALB (Table 4). Temperature was the highest and positive effect on the water diffusivity (Table 5). The change in temperature from 60 to $80^{\circ} \mathrm{C}$ caused an increase in the diffusion coefficients for both the foams and pulp, especially for the EMB foams, where the diffusivity value doubled in relation to that obtained at $60^{\circ} \mathrm{C}$ (Table 3 ).

An increase in foaming agent concentration caused an increase in $D_{\text {eff }}$ in relation to that of the mango pulp, a result that was to be expected because the formation of a porous structure improved the capacity for the exit of water from the food. ${ }^{[16,31,33]}$ The porous structure of the ALB foam was achieved due to interactions with bubble walls (lamella) by electrostatic or hydrophobic forces, hydrogen bonds or covalent linkages. ${ }^{[5]}$ Meanwhile, EMB was adsorbed on the air-water interface, reducing the free energy, that consequently diminished interfacial surface tension. ${ }^{[49]}$

However, as shown in Table 5, the negative effect of the interaction between the concentrations of EMB and ALB tended to decrease the value of $D_{\text {eff. It }}$ was more evident at the lower temperature, because the effects of the temperature were less pronounced on the diffusivity, as shown in Table 3 and also by the fitted model for the responses, which can be calculated through the substitution of the coefficients (Table 5) and codified variables in Eq. (9).

The diffusion coefficients obtained in the present study were much lower than those reported by Wilson et al. ${ }^{[43]}$ and Rajkumar et al. ${ }^{[13]}$ for the foam mat drying of mango pulp with albumin, where the values reported for the diffusion coefficients were around $1.53 \times$ $10^{-8} \mathrm{~m}^{2} \cdot \mathrm{s}^{-1}$ for process temperatures of $65^{\circ} \mathrm{C}$ and 
$2.63 \times 10^{-8} \mathrm{~m}^{2} \cdot \mathrm{s}^{-1}$ at $85^{\circ} \mathrm{C}$. For the drying of shrimp foam, Azizpour et al. $^{[50]}$ found values of $3.51 \times$ $10^{-8} \mathrm{~m}^{2} \cdot \mathrm{s}^{-1}$ at $85^{\circ} \mathrm{C}$. The authors calculated the diffusivity based on the analytical solution of the diffusion equation for plates, but only used the first term of the series, which is usually adequate for numbers greater than 0.2 , because the series converges quickly for this condition. The same simplification was tested in the present study and resulted in high values for diffusivity, also to the order of $10^{-8} \mathrm{~m}^{2} \cdot \mathrm{s}^{-1}$, proving that this approximation would be inadequate for the drying of these foams.

\section{Conclusion}

Foam mat drying was shown to be a viable method to obtain mango powders and maintain their physical and nutritional properties. The foaming agents of albumin and the emulsifier blend significantly affected the color parameters of the dehydrated pulp, resulting in a lighter color than the product without the additives and maintaining a yellow tonality, results similar to those of powders produced by traditional methods such as spray drying. Albumin and the emulsifier blend also exerted positive effects on the retention of total carotenoids during the drying of the foams, always resulting in greater retention than in the powders obtained from pulps without additives, the maximum value being obtained at $80^{\circ} \mathrm{C}$ with $10 \mathrm{~kg}$ ALB $\cdot 100 \mathrm{~kg}^{-1}$ pulp (88.9\% retention). The temperature also positively affected retention, this result being attributed to the shorter drying time. The solubility was not affected by the temperature or by the concentration of the foaming agents. High values were obtained for the water diffusion coefficient $\left(D_{\text {eff }}\right)$, allowing for low moisture contents and water activities to be attained in short drying times. The diffusivity was estimated based on Fick's law, and taking shrinkage into consideration allowed for very efficient fits to the model, showing it to be adequate to represent the foam mat drying process.

\section{Funding}

The authors are grateful to the State of São Paulo Research Foundation (FAPESP) for the scholarship (process 2012/ 21428-6) and financing (process 2014/11514-8).

\section{References}

[1] Food and Agriculture Organization of the United Nations (FAOSTAT). Production quantities of mangoes, mangosteens, guavas by country. Avaliable at http://faostat3.fao.org/browse/Q/QC/E (acessed June 19, 2015).
[2] Ribeiro, S.M.R.; Schieber, A. Bioactive compounds in manga (Mangifera indica L). In Bioactive Foods in Promoting Health: Fruits and Vegetables; Watson, R.R., Preedy, V., Eds.; Elsevier: Burlington, MA, 2010; 507-523.

[3] Sagar, V.R.; Suresh, P. Recent advances in drying and dehydration of fruits and vegetables: A review. Journal of Food Science and Technology 2010, 47(1), 15-26.

[4] Guiné, R.P.F.; Henrriques, F.; João Barroca, M. Mass transfer coefficients for the drying of pumpkin (Cucurbita moschata) and dried product quality. Food and Bioprocess Technology 2009, 5(1), 176-183.

[5] Hardy, Z.; Jideani, V.A. Foam-mat drying technology: A Review. Critical Reviews in Food Science and Nutrition. In press. doi:10.1080/10408398.2015.1020359.

[6] Kadam, D.M.; Wilson, R.; Kaur, V.; Chadha, S.; Kaushik, P.; Kaur, S.; Patil, R.; Rai, D.P. Physicochemical and microbial quality evaluation of foam-mat-dried pineapple powder. International Journal of Food Science \& Technology 2012, 47(8), 1654-1659.

[7] Bag, S.; Srivastav, P.; Mishra, H. Optimization of process parameters for foaming of bael (Aegle marmelos L.) fruit pulp. Food and Bioprocess Technology 2009, 4(8), 1450-1458.

[8] Kandasamy, P.; Varadharaju, N.; Kalemullah, S.; Maladhi, D. Optimization of process parameters for foam-mat drying of papaya pulp. Journal of Food Science and Technology 2012, 51(10), 2526-2534.

[9] Rajkumar, P.; Kailappan, R.; Viswanathan, R.; Raghavan, G.S.V. Drying characteristics of foamed alphonso mango pulp in a continuous type foam mat dryer. Journal of Food Engineering 2007, 79(4), 1452-1459.

[10] Zheng, X.; Wang, Y.; Liu, C.; Sun, J.; Liu, B.; Zhang, B.; Lin, Z.; Sun, Y.; Liu, H. Microwave energy absorption behavior of foamed berry puree under microwave drying conditions. Drying Technology 2013, 31(7), 785-794.

[11] Muthukumaran, A.; Ratti, C.; Raghavan, V.G.S. Foammat freeze drying of egg white and mathematical modeling. Part I: Optimization of egg white foam stability. Drying Technology 2008, 26(4), 508-512.

[12] Kadam, D.M.; Wilson, R.A.; Kaur, S. Determination of biochemical properties of foam-mat dried mango powder. International Journal of Food Science \& Technology 2010, 45(8), 1626-1632.

[13] Rajkumar, P.; Kailappan, R.; Viswanathan, R.; Raghavan, G.S.V.; Ratti, C. Foam mat drying of alphonso mango pulp. Drying Technology 2007, 25(2), 357-365.

[14] Raharitsifa, N.; Ratti, C. Foam-mat freeze-drying of apple juice. Part 1: Experimental data and ann simulations. Journal of Food Process Engineering 2010, 33(2010), 268-283.

[15] Auisakchaiyoung, T.; Rojanakorn, T. Effect of foam-mat drying conditions on quality of dried Gac fruit (Momordica cochinchinensis) aril. International Food Research Journal 2015, 22(5), 2025-2031.

[16] Sangamithra, A.; Sivakumar, V.; Gabriela, J.S.; Kannan, K. Optimization of foaming properties and foam mat drying of muskmelon using soy protein. Journal of Food Process Engineering 2016, 39(6), 692-701.

[17] Abbasi, E.; Azizpour, M. Evaluation of physicochemical properties of foam mat dried sour cherry powder. $L W T$ - Food Science and Technology 2016, 68, 105-110. 
[18] Chaves, M.; Barreto, I.; Reis, R.; Kadam, D. Physicochemical and sensory properties of purple Brazilian cherry (Eugenia uniflora, L.) foams. International Journal of Food Science \& Technology 2013, 48(8), 1688-1697.

[19] Zheng, X.-Z.; Liu, C.-H.; Zhou, H. Optimization of parameters for microwave-assisted foam mat drying of blackcurrant pulp. Drying Technology 2011, 29(2), 230-238.

[20] Falade, K.O.; Adeyanju, K.I.; Uzo-Peters, P.I. Foam-mat drying of cowpea (Vigna unguiculata) using glyceryl monostearate and egg albumin as foaming agents. European Food Research and Technology 2003, 217(6), 486-491.

[21] Azizpour, M.; Mohebbi, M.; Hosein, M.; Khodaparast, H. Effects of foam-mat drying temperature on physicochemical and microstructural properties of shrimp powder. Innovative Food Science and Emerging Technologies 2016, 34, 122-126.

[22] Franco, T.S.; Perussello, C.A.; Ellendersen, L.N.; Masson, M.L. Effects of foam mat drying on physicochemical and microstructural properties of yacon juice powder. $L W T$ Food Science and Technology 2016, 66, 503-513.

[23] Fortes, M.; Okos, M. Drying theories: Their bases and limitations as applied to food and grains. In Advances in Drying; Mujumdar, A., Ed.; Hemisphere Publishing: New York, 1980; 119-154.

[24] Crank, J. The Mathematics of Diffusion; Oxford University Press: London, 1975.

[25] Garcia, C.C.; Mauro, M.A.; Kimura, M. Kinetics of osmotic dehydration and air-drying of pumpkins (Cucurbita moschata). Journal of Food Engineering 2007, 82(3), 284-291.

[26] Francis, F. Colorimetric properties of food. In Engineering Properties of Food; Roo, M.; Syed, S.; Rivzi, K., Eds.; CRC Press: Boca Raton, FL, 2005; 703-732.

[27] Rodriguez-Amaya, D.; Kimura, M. Handbook for Carotenoid Analysis; HarvestPlus: Washington, DC, 2004.

[28] Murphy, E.W.; Criner, P.E.; Gray, B.C. Comparisons of methods for calculating retention of nutrients in cooked foods. Journal of Agricultural and Food Chemistry 1975, 23(6), 1153-1157.

[29] Caparino, O.A.; Tang, J.; Nindo, C.I.; Sablani, S.S.; Powers, J.R.; Fellman, J.K. Effect of drying methods on the physical properties and microstructures of mango (Philippine 'Carabao' var.) powder. Journal of Food Engineering 2012, 111(1), 135-148.

[30] Montgomery, D. Design and Analysis of Experiment; John Wiley \& Son: New York, 2001.

[31] Karim, A.; Wai, C. Foam-mat drying of starfruit (Averrhoa carambola L.) pure Stability and air drying characteristics. Food Chemistry 1999, 64(3), 337-343.

[32] Chauhan, A.K.; Patil, V. Effect of packaging material on storage ability of mango milk powder and the quality of reconstituted mango milk drink. Powder Technology 2013, 239, 86-93.

[33] Gupta, K.; Alam, M. Mass and color kinetics of foamed and non foamed grape concentrate during convective drying process: A comparative study. Journal of Engineering and Technology Research 2014, 6(4), 48-67.

[34] Gupta, K.; Alam, S. Formulation and optimization of foam mat dried grape bar. Agricultural Engineering International: CIRG Journal 2014, 16(4), 228-239.
[35] Pott, I.; Marx, M.; Neidhart, S.; Mühlbauer, W.; Carle, R. Quantitative determination of -carotene stereoisomers in fresh, dried, and solar-dried mangoes (Mangifera indica L). Journal of Agricultural and Food Chemitry 2003, 51(16), 4527-4531.

[36] Damodaran, S., Parkin, K.; Fennema, O. Fennema's Food Chemistry; CRC Press: Boca Raton, FL, 2008.

[37] Sramek, M.; Schweiggert, R.M.; van Kampen, A.; Carle, R.; Kohlus, R. Preparation of high-grade powders from tomato paste using a vacuum foam drying method. Journal of Food Science 2015, 80(8), E1755-E1762.

[38] Bergenståhl, B. Physicochemical aspects of a emulsifier functionality. In Food Emulsifiers and Their Applications; Hasenhuettl, G.; Hartel, R., Eds.; Springer: New York, 2008; 173-190.

[39] Mishra, P.; Mishra, S.; Mahanta, C.L. Effect of maltodextrin concentration and inlet temperature during spray drying on physicochemical and antioxidant properties of amla (Emblica officinalis) juice powder. Food and Bioproducts Processing 2014, 92(3), 252-258.

[40] Wilson, R.A.; Kadam, D.M.; Chadha, S.; Grewal, M.K.; Sharma, M. Evaluation of physical and chemical properties of foam-mat dried mango (Mangifera Indica) powder during storage. Journal of Food Processing and Preservation 2014, 38(4), 1866-1874.

[41] Valenzuela, C.; Aguilera, J.M. Aerated apple leathers: Effect of microstructure on drying and mechanical properties. Drying Technology 2013, 31(16), 1951-1959.

[42] Ratti, C.; Kudra, T. Drying of foamed biological materials: Opportunities and challenges. Drying Technology 2006, 24(9), 1101-1108.

[43] Wilson, R.; Kadam, D.; Chadha, S.; Sharma, M. Foam mat drying characteristics of mango pulp. International Journal of Food Science and Nutrition Engineering 2012, 2(4), 63-69.

[44] Rahman, S. Food Properties Handbook; CRC Press: Boca Raton, FL, 1995.

[45] Chirife, J.; Fontan, C.F.; Benmergui, E.A. The prediction of water activity in aqueous solutions in connection with intermédiate moisture foods IV. $a_{w}$ prediction in aqueous non electrolyte solutions. International Journal of Food Science \& Technology 1980, 15(1), 59-70.

[46] Bull, H. Adsorption of water vapor by proteins. American Chemical Society 1944, 66, 1499-1507.

[47] Thuwapanichayanan, R.; Prachayawarakorn, S.; Soponronnarit, S. Drying characteristics and quality of banana foam mat. Journal of Food Engineering 2008, 86(4), 573-583.

[48] Djaeni, M.; Prasetyaningrum, A.; Sasongko, S.B.; Widayat, W.; Hii, C.L. Application of foam-mat drying with egg white for carrageenan: Drying rate and product quality aspects. Journal of Food Science and Technology 2013, 52(2), 1170-1175.

[49] Hunter, T.N.; Pugh, R.J.; Franks, G.V.; Jameson, G.J. The role of particles in stabilising foams and emulsions. Advances in Colloid Interface Science 2008, 137(2), 57-81.

[50] Azizpour, M.; Mohebbi, M.; Khodaparast, M.; Varidi, M. Optimization of foaming parameters and investigating the effects of drying temperature on the foam-mat drying of shrimp (Penaeus indicus). Drying Technology 2014, 32(4), 374-384. 